\title{
Performance indicators and standards for Polish research libraries
}

\author{
Lidia Derfert-Wolf, Ewa Dobrzyńska-Lankosz, Wanda Dziadkiewicz, Mirosław \\ Górny, Elżbieta Górska, Marek M. Górski, Artur Jazdon, Anna Sokołowska-Gogut \\ and Teresa Wildhardt
}

\begin{abstract}
Authors
All the authors are members of an informal team "The Task Group for Standardization". They are Chief Librarians or Deputy Librarians and represent various types of the Polish research libraries. Miroslaw Gorny is a Head of Information Systems Division at the Institute of Linguistics of the Adam Mickiewicz University in Poznan.

Email: lidka@atr.bydgoszcz.pl or mgorny@main.amu.edu.pl
\end{abstract}

\begin{abstract}
The article discusses proposed standards for Polish research libraries evaluation. At the beginning, the authors present the situation of research libraries in Poland. They write about the effects of the social-political transformation in the 90s, present selected statistical data, and describe the progress in computerisation. The following part of the article relates to the currently applied in Poland standards of library evaluation. Discussed are e.g. the presently applied tools for data collection and analysis. The last part includes proposed methods for the preparation of standards and assessments for Polish research libraries.
\end{abstract}

\section{Introduction}

The article presents some reflection on the preparatory work on methods for the Polish research libraries evaluation and to discuss the current state of affairs in the preparation of countrywide uniform standards. As LIRN readers might not be familiar with Polish libraries issues, we have decided to precede the main text with some background data. Due to obvious limitations, only research libraries have been put under scrutiny. However, it should be noted that library and information services are also provided by a large number of public (in 2001 there were 8849 public libraries), school, pedagogical and many other libraries. The year 1989 has been adopted as the turning point being the time of the introduction of the political changes in the wake of which Poland has become a fully democratic country. A short presentation of libraries prior to that date is also included.

In subsequent parts of the article we examine the current situation in relation to the issues of library statistics and the developments in the preparation of performance indicators. A specially prepared computer program of collecting quantitative and qualitative data is described in detail.

Finally, new proposals for working out effective evaluation methods, tools for libraries and countrywide adopted standards, which should be regarded as a contribution to the discussion on further studies and, possibly, an invitation to a cooperation with libraries of other countries, are presented and discussed. 


\section{General characteristic on Polish research libraries}

A group of "research libraries" was formed before 1989 in a parliament act and encompassed libraries with a very diversified character, size, and institutional membership. The common feature of the group was the task the libraries had to fulfil in relation to science and education programmes. One of the characteristic traits was the dependency of the libraries on the communist political system which resulted in, first of all, insufficient hard-currency and the state monopoly of scientific periodicals and foreign books acquisition. The research libraries had limited opportunities to cooperate at a local or regional level, despite the fact that, formally, an all-nation library network existed. The period between 1982 and 1989, despite the detrimental effect of the material law imposed by the authorities upon the cultural life of the country (meagre publishing market), was fairly favourable financially for public libraries. The resources obtained from the then National Fund for the Development of Culture enabled a substantial improvement in the library infrastructure and widening their services to the general public.

The political and social changes of 1989 that brought down the undemocratic governments and the economic transformations they induced presented for the libraries a major revolution in itself. When we overlap this with the transformations stimulated by automation, it is plain to see how much had to be, and in fact was, changed (Kniffel, 2001; Modern Libraries and Librarianship in Poland, 1995).

The Library Act of 1997 determines that the group of research libraries [Table 1] is composed of the National Library, university libraries, libraries of research and development units, selected public libraries and other. A few public research libraries play an important role in the system because of the status of their holdings and the number of serviced patrons. This group of 12 (as of 31.12.2002) public libraries includes as many as 10 which also serve as municipal libraries and which, along with the service they render to the local community, provide essential guidance to public libraries comprising a library network within a given province.

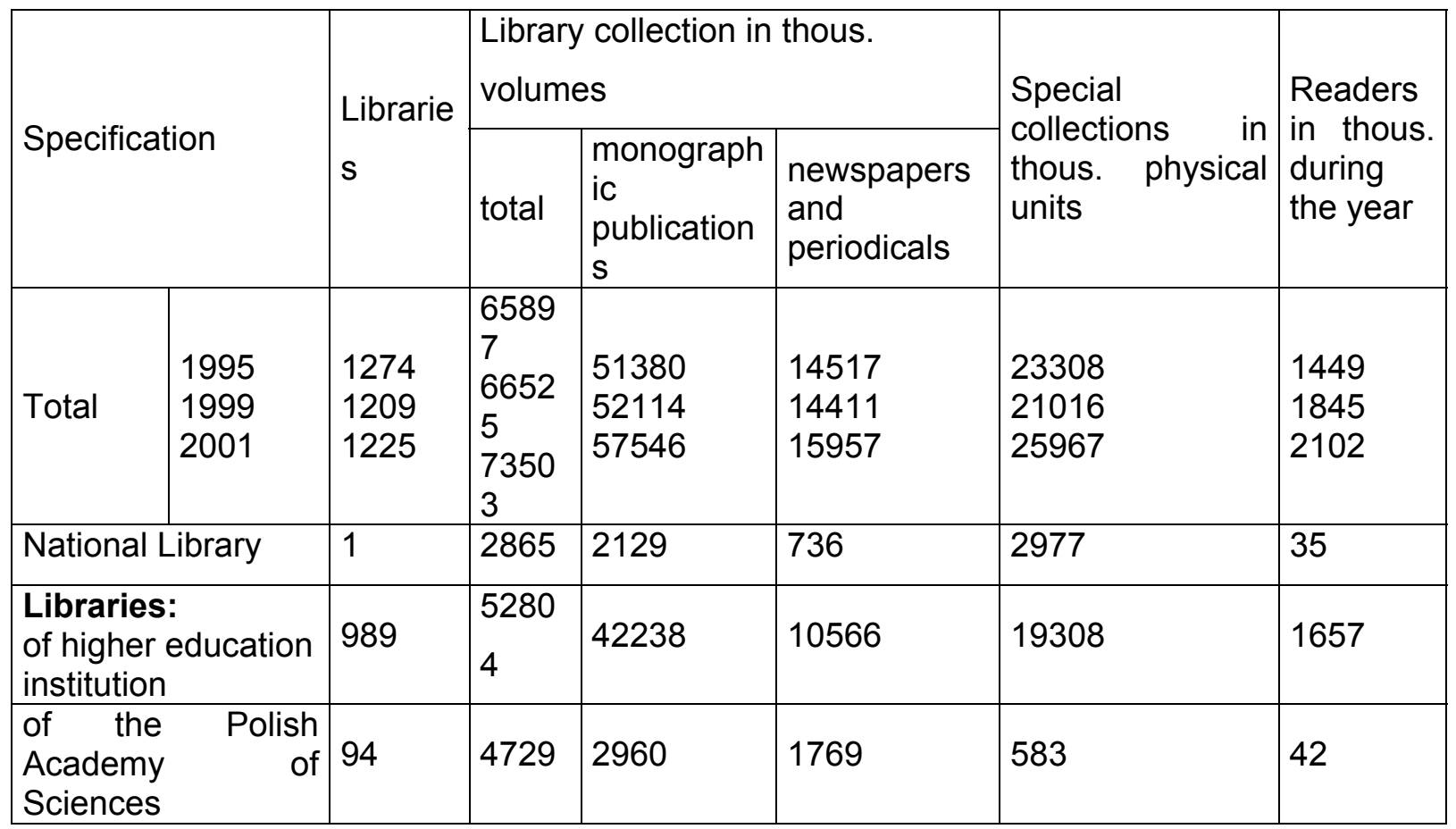




\begin{tabular}{|l|l|l|l|l|l|l|}
\hline $\begin{array}{l}\text { of branch research- } \\
\text { development units }\end{array}$ & 99 & 2867 & 2062 & 805 & 1093 & 37 \\
\hline Public & 11 & 6386 & 5391 & 995 & 1463 & 250 \\
\hline Others & 31 & 3852 & 2766 & 1086 & 543 & 81 \\
\hline
\end{tabular}

Table 1: Research libraries (main and subsidiary) - as of 31.12.2001 (Statistical Year Book, 2002)

The financial situation of libraries has fundamentally changed, and, what followed, has influenced their capability to perform their statutory functions. Academic libraries are financed by the budgets of their parent institutions which come from the resources of the appropriate ministries. For the bulk of the academic libraries, the superior authority is the Ministry of National Education and Sport. These basic funds cover current expenditure. The libraries are also supported from the Committee of Scientific Research which apportioned extra funding in special projects such as automation, preservation of holdings and others. However, due to drastically low budgets apportioned to science at the national level, the funds are insufficient and not satisfactory. Fortunately, new opportunities have emerged in obtaining extra funds from various foundations. Librarians have now a free choice in purchasing new books and titles of periodicals, and in choosing electronic resources. We have started to learn a new type of management of finances, tender procedures, the "ins and outs" of how to negotiate or set up consortia to reach economically viable joint access to resources.

The political and social changes in the country have had a great effect on the financial situation of public libraries. Between 1990 and 1998 all the municipal public libraries had the status of state cultural institutions and were financed from the state budget, while the remaining libraries became local government institutions financed by local authorities. The administrative reform of the 1999 have caused deterioration in the financial situation of the libraries - all the public libraries, including former municipal libraries, are now financed by local authorities. This, in effect, means worsening of the working conditions for all of the public libraries with the status of a research library.

There has been a rapid increase in the number of full-time and extra-mural students at universities since 1989. The number of students has tripled. A notable segment is formed by students of newly established non-state-owned, private universities and institutions of higher education, whose libraries are weak and underdeveloped. Servicing such a huge number of patrons with only a slightly increased number of staff required a change in the approach to the problem of the quality and effectiveness of work, its structural changes and the organization. This approach gave libraries a boost to encourage staff education and training. New opportunities of participating in projects such as TEMPUS, or the PULMAN network and chance to gain access to supporting funds from the Open Society Institute effected in beneficial changes.

The year 1989 may be regarded as a turning point in automation of research libraries (Research Libraries, 1999). The Western producers of integrated library systems found the emerging Polish market attracting and promising. In the meantime, many scientific institutions gained substantial financial support from foreign foundations, mainly from the A.W. Mellon Foundation, but also from OSI and PHARE. 
From among those offered, some systems such as VTLS/Virtua, Horizon, Aleph, Tinlib, Q-Series, and Innopac were purchased and have been in operation ever since. Polish systems are also in use, including Sowa, MAK and Prolib although they do not fully comply with requirements for up-to-date library systems.

In 1993, the Union Authority File was initiated, and in 2002 the National Union Catalog NUKAT (2001). In parallel, there is a distributed catalogue of Polish libraries KaRo (2001), which currently enables searching of the resources of 58 Polish libraries.

Other directions in automation are the creation of bibliographic and factographic databases by libraries themselves, access to commercial sources of information (databases and electronic journals), projects of digitisation of own collections, e.g. Digital Library of Wielkopolska (2002), Virtual Library of Polish Literature (2000), Virtual Scientific Library (2003), Treasury of Polish Literature (1999), Archive of the Electronic Collection of the Central Library of AGH University of Science and Technology (2000).

The positive changes also include floor space development and the change in the approach to collection preservation. The modern building of Warsaw University Library was built, the library of the Jagiellonian University in Kraków got an extension, the work on new buildings of libraries in many other cities were initiated. 53 research libraries have been designated to collect the so-called National Library Resource i.e., resources of the most valuable items for Polish culture and science. Preservation works on a much larger scale have been initiated, such as the governmental project entitled "acidic paper", and detection systems have been introduced in many libraries.

Many changes have also taken place in professional activities. The Association of Polish Librarians has become free of the political control. Representatives to the National Library Council are chosen in a different way now. A new autonomous controlling body has emerged - the Council of Directors of Libraries of Institutions of Higher Education. All-nation discussion groups and the "Elektroniczna Biblioteka" EBIB - Electronic Service for Librarians (1999) have all contributed to forming a new identity of the library community.

\section{Library Statistics and Performance Indicators - the current state of affairs and the draft version of the data collection project}

Every second year the Main Statistical Office collects the following data from libraries: library collections (expenditures on the items are not included), library premises, registered users, circulation, and library staff. Since 2000 the libraries have been requested to send additional data on: implemented computer system, databases produced by libraries, including OPACs, CD-ROM databases, on-line access to databases and their number, computer equipment, access to the Internet for the staff and users and expenditures. However, there are no uniform standards and evaluation methods for library assessment. Those currently used are predominantly in-house produced by particular units or groups of units and, in the main, deal with the issues of library organisation, employment and working hours. The main problem hampering proper library evaluation is the lack of suitable data systematically collected and precisely describing library activity as, in the present circumstances, those collected by the Statistical Office are completely insufficient. First of all, they lack information on finances and the services provided by libraries. Data on human 
resources and the infrastructure are very schematic. Educational activity is completely left out in the hitherto produced reports. There is no place for electronic sources of information other than databases.

The research work done so far focused only on selected library processes (Górny \& Jazdon, 997; Górny \& Jazdon \& Nowak, 1999). No complex statistical research has been carried out which would allow us to embark on detailed and penetrating comparative analysis of libraries of a certain type in relation to other libraries of the same type in the country and abroad. The Task Group for Standardization (hereafter referred to as "The Group") was established in 2001during the conference organized by the Main Library of the Cracow University of Economics - "Comparative Research of Polish Research Libraries". They found the prototypes for this kind of research in the government projects of the EU countries and the US. The statistics produced by LibEcon (2000), IPEDS (2003), and Deutsche Bibliotheks Statistik (2003) similar national and international projects came as additional supporting material (The Follett Report, 1993; EQUINOX, 2002; ACRL Standards \& Guidelines, 2003; CAUL Council of Australian University Librarians, 2003). International standards in library statistics and performance indicators such as ISO 11620 (1998) also formed the base material.

The research libraries in Poland have begun their work on creating a comparative platform which would be used by chief librarians. It would be useful for vice-chancellors of universities and the financing bodies to universities or public libraries, e.g. the Ministry of National Education and Sport or the Ministry of Culture as well as Polish and international university accreditation commissions. The preliminary work was already taken up during a few conferences. The aim was to interest the academic community in the project and to set up the Group, which would work out a database of the indicators enabling the proper assessment of a library or a group of libraries of a certain type.

In the first place, the Group worked out a questionnaire for comparative studies. It was based on the questionnaire prepared for the Cracow conference and on another implemented within the TEMPUS JEP project 13242-98 "Development of Library Management as a Part of the University Total Quality Management". The project was realized in 1998-2001, with the participation of the libraries of the following universities: Cracow University of Technology (project co-ordinator), University of Technology and Agriculture in Bydgoszcz, Szczecin University, Kielce University of Technology, Delft University of Technology, University College London, Universidad de Cadiz, National Technical University of Athens. The questionnaire includes all the elements of the library system, surrounding matters and the library processes and services. All these elements have been grouped into the following sections: staff, library holdings, budget, infrastructure, circulation, information services, education, publishing programmes, own databases, co-operation, and professional activity. The answers to the questions require the use of numerical data (describing e.g. the size of the collection, acquisitions, etc.), indicators expressed in percent or a simple YES/NO reply (e.g. OPAC availability). The final part of the questionnaire deals with the selected performance indicators, e.g.:

- library expenditures per user,

- expenditures on purchases of books per user,

- library budget as the percentage in the budget of the university,

- time needed for preparation of document,

- computer-catalogued holdings as a percentage of the whole holdings, 
- percentage of catalogue records obtained from outside sources.

The remaining indicators will be calculated automatically on the basis of numerical data obtained from the questionnaires according to prescribed patterns. Here are some of the most important:

- number of registered users as a percentage of the number of potential users

- number of books per user,

- number of users per library employee,

- library floor space per user,

- number of users per seat available in reading rooms,

- number of loans per registered user,

- number of loans per library employee.

The working out of the questionnaire required much consultation and comparative study with the available literature of the subject and with the standards in operation in other countries (Abbott 1994); (Blixrud, 2001); (Cullen \& Calvert, 1995); (Kokkonen, 1996); (Poll, 2001); The Effective Academic Library, (1995); Guidelines for College Libraries, (1995). We tried to select questions in such a way that the answers to them would require information that would be easily accessible and calculable as well as more or less uniform for all of the libraries. The data which have not appeared in the questionnaires of the Main Statistical Office but have been included in our questionnaire include all the data on the utilization of electronic sources, remote access to library services, costs of purchase of electronic resources, costs of automation and their share in the library budget.

Moreover, the differences in functions of libraries (academic, public) and the organizational structures of research libraries needed to be taken into consideration. Another problem that emerged had to do with faculty libraries of a university, which reported either to the central library or to relevant faculties. To avoid this, we decided to collect data pertaining exclusively to central libraries. Still another problem was to establish a group of users to which the selected indicators were applicable. We do not have anything comparable to the indicator described in other countries as the FTE student model. For the purpose of the present inquiry and prospective further studies the working procedure has been adopted. Calculation of the above mentioned indicators is made in relation to the general number of users (in the case of academic libraries, it is the total number of students and the employees of a university), plus additionally, the number of students and the number of full-time students. To dismiss any doubt, each of the questions that might be doubtful is accompanied with a suitable explanatory footnote or even with a suitable formula to be used.

Another task the Group was charged with was the preparation of a computer program that would tackle the collection and the analysis of the data from the questionnaires once they had been filled in on-line by the representatives of the libraries. The University of Technology and Agriculture in Bydgoszcz has prepared the conception and the basic version of the program. The project is financed from the funds of the Ministry of National Education. The working beta version of the Internet-applicable application includes the following elements:

- Internet-accessible web-site

- database

- administrator's module 
- module for librarians to retrieve from and upload data to the on-line questionnaire (electronic version of the above described questionnaire)

- module for the statistical analysis.

The web-site has direct links to the information on the project, instruction of use, questionnaires, results of previous studies and useful links to other sites dealing with standardization, performance indicators and library statistics. The instruction covers such major steps as registration of a library and the description of the work with questionnaires (how to fill them in, authorization, and data analysis). The site also includes closing dates for handing in the questionnaires for a given year. The page labelled "Results of the Study" will include the collective analyses of data from all of the libraries involved in the project and will be presented in numbers and in charts according to adopted criteria.

The database is designed to incorporate and register the data from the questionnaires. It has been given a dynamic form, i.e. the administrator is in position to change, add or delete any fields corresponding to the questions from the questionnaire at any time. Moreover, with every instance of activating the database, a suitable questionnaire will be automatically displayed e.g., the questionnaire for public libraries will not include questions and indicators pertaining to students, etc. Additionally, the database has built-in mathematic formulae which control and verify automatically the accuracy of the filled-in fields, and formulae to calculate selected performance indicators.

The administrator's module will serve to register libraries and persons entitled to transmit data and work out collective analyses. The registration will include sending a form to the administrator with the following data: name and type of the library, university status (state-owned, non state-owned), name, telephone number, e-mail and suggested username.

Another module will be designed for individual work (within a single library). The highest authority will be that of a director who will be in position to fill in the questionnaire, modify the data, send data to the database and, finally, authorize them. Upon the authorization of the questionnaire by the director, the performance indicators, which are not present in the questionnaire, will be automatically calculated and displayed. The director may delegate powers to appointed library employees who will be entitled to fill in certain segments of the questionnaire themselves. There will also be a possibility to produce multifaceted analysis of the data according to various adopted criteria, for example, according to selected timeframe or during selected longer periods.

The last module, the most important from the perspective of further studies, will be used by the Group exclusively. It will serve as a tool to carry out collective analyses based on the data and the performance indicators from all of the libraries. The analyses will be made through a preliminary selection of the types of libraries, a given year or a timeframe, type of the chart or the results of the calculated data (arithmetic average number, median, maximal value, minimal value). The next choice will be that of a category of the data or indicators and their combinations.

\section{Evaluation and standarization methods in Polish research libraries - a proposal of a study project}


The above-described computer program for collecting and presenting statistical data and performance indicators is designed to suffice for a several year study aimed at establishing a procedure for Polish library evaluation and at preparing a set of standards applicable to these libraries.

While preparing the project, some provisions and basic assumptions had to be put forward:

1) Introduction of a division of information sources into those of national heritage and cultural importance and those satisfying everyday information needs. The National Heritage Repository should not be submitted to appraisal and standards normally applied to the operational repository. It does not mean, however, that no norms should be established for the Repository, but that they ought to be agreed on matters concerning its safe storage and the way it should be made available to the general public.

2) The division of the library viewed as an institution into:

- information resources (books, periodicals, other sources of information - as regards their content and not medium, the number of volumes, technical conditions of making them available, etc.),

- organizational and technological infrastructure (everything that deals with the organization and the technical facilities needed to fulfil the regulation of processes of acquisition, preparation of material, storage and circulation),

- auxiliary base (maintenance staff and equipment needed for making proper functioning of a library)

This division ensues from a very distinct line between the content of the source of information and the infrastructure needed for providing the service. The same contents can be made available through different organizational and technological platforms. All the librarian needs to be able to determine is to establish what kind of information the user needs and then simply retrieve it. But the character of the infrastructure used for retrieving this information is entirely in their hands. However, it is the knowledge, expertise and professional skills of the librarian that will decide on the costs of the process of the retrieval of information, its duration, comfort and ease of its distribution, its format, etc.

3) Methods of formulating library tasks. It has been assumed that they are formulated according to the following pattern: Who $<$ Recipient $>$ (group of users characterized by appropriate attributes) will be given access to What resources (characteristics of resources) and, finally, on What conditions (characteristics of conditions)?

Obviously, there are no strict rules determining what should be included in all of the three elements of the pattern. However, any task the library is facing should reflect this general pattern. By the recipient, we mean distinguishable groups of users differentiated by their information needs, abilities in making use of the library infrastructure and so on. At this point, the library can also determine how many users it is in position to service properly. The label "To what resources" is only the authentic appraisal of the capabilities of the library. For instance, due to financial constraints, only a selected group of users is allowed to have access to certain sources of information, while other groups are not. Having evaluated accurately its financial possibilities, the library can correctly determine whether it is in position to facilitate access to articles in the document delivery service system only to research and 
academic staff of its university. The last element, "On what conditions" may refer to the duration of processing an order, the access time to the source, the sum the library cannot exceed while purchasing sources, etc. Specification of the conditions of making a source available (always for a given group of users and for a given group of resources) makes the library aware of the need for constant performance measurement and prevents it from being vulnerable to, not always justified, demands on users.

\section{Library evaluation - proposals}

The library evaluation has multiple significance. For the superior authorities, it is a direct measure of the usefulness of the library and its functioning. For the management of the library, it helps in pinpointing problem areas. In both cases though, the evaluation has a diagnostic significance. Modern libraries are very diversified when it comes to the type of service they provide and the way they function. This naturally hampers any attempt at making any general evaluation. The fact that libraries are non-profit institutions makes the situation even more complicated. Otherwise, the gained profit could be an easily applicable and very transparent criterion to be adopted in the evaluation.

How should then the evaluation elements be constructed? Apparently, the most important evaluation element is the one given by its users. A student satisfaction survey is, however, relatively expensive and time-consuming. To some degree, the analysis of the level of the use of resources can replace the satisfaction survey. Moreover, the results presented in it give a lot of information on the real use of the library and are not only a set of opinions on the functioning of the library. Perhaps the best possible solution would be to employ both study techniques simultaneously.

Therefore, the level of the use of resources (M1) has been adopted as the main indicator in the evaluation. However, immediately two problems arise - how to measure the use of the resources and how to interpret the results of such measurements? Everything that the library can give access to is regarded as information resources (including items that come from other sources, like interlibrary loans, access to commercial full-text databases and electronic journals, document delivery service etc.). The library can potentially meet some of the needs in information services in relation to access to the mentioned resources in a given time. A special algorithm can be used to calculate the number. Knowing the real number of the "information transactions" and comparing it to the number of potential instances of "information transactions", we can determine the actual use of the resources and then make the evaluation against the assumed scale of preference.

Another measure unit employed (M2), with auxiliary and verifying character, especially in the case of heavy use of the resources, is the number of information services transactions in relation to the number of registered (or potential) users. This unit of measure is based on the assumption that the average number of services used by the user apportioned to a given category is approximately known. If the substantial majority of the information users reach the average value, it means that it is highly improbable that information needs which are not satisfied do exist.

Auxiliary measure unit (M3) may be the number of information demands (as opposed to needs i.e., for example, a presented call slip requested for certain items which are otherwise available in the system), which have not been responded to in relation to the total number of information demands. 
The most difficult problem to be solved is to work out the definition of services and information demands in such a way that it would be possible to construct easily applicable indicators based on them. It seems proper to assume such elements like transaction of loan, the number of hours spent by the users in reading rooms and catalogue rooms and the number of log-ins to the library systems as information service transactions. To compare such types of service, a standard unit any given service can be converted to has to be introduced.

\section{Standards - proposals}

The attempt at working out and subsequent application of the standards is designed to:

a) make the library develop its information resources and technological and organizational platforms so that individual user groups can have a certain minimum access level to relevant information resources. Generally speaking, what is meant is a certain quality level of information services.

b) assist the library in the realisation of the statutory tasks through localizing the socalled critical points and determining suitable standards for them.

There are at least three categories of norms. The first category is the group of standards connected with the quality of the end-product. It is fairly easy to indicate a product which may be regulated by norms. It is much more difficult to determine a product that should be standardised. Introduction of detailed norms which would apply to each and every type of service could, however, successfully prevent any library form effective managing. Therefore, only some of the services should be selected.

The second category of norms should deal with the key elements of the library process. They should, being a sufficient safeguard of quality of provided services, play the role of instruments controlling the functioning of the system. The norms, whose principal task is to improve the functioning of the system, must regulate those processes which may have the biggest influence. These norms are purely technical and inform us how to initiate and use a given process.

The third category of norms is of auxiliary character. These standards may apply to particular departments in the library or to library processes. They determine the size of the resources to be involved in a facilitation of a given process taking into consideration given conditions.

What has to be done then is to work out a series of norms dividing them into those of: quality, technology and support in providing access to sources and in service and costs involved. As far as quality norms are concerned, the most important for the user are probably the following two parameters: access to the largest number of significant sources of information and the shortest time of retrieving them. Thus, the standards, when introduced, should make these characteristic features of the information transaction permanent - a certain required level of completeness and acceptable average time to process a request (at least, not exceeding given values).

Within the quality standard groups the following standards have been differentiated:

1) Standards pertaining to information resources

a/ the need to obtain complete metadata for the serviced discipline at the level approaching 100 per cent, or the highest level possible.

b/ access to not less than $20 \%$ of the sources from a given discipline, with the careful selection of those most important, and access to complete information and assistance 
with the most favourable selection and choice of sources. Full information on the metadata will allow the user to evaluate the literature on a given subject in a given sphere of learning, and adopt a suitable strategy on how to proceed in order to retrieve the information needed.

c/ access to at least $20 \%$ of the information sources from a given discipline reported by the information users (no assessment, the only criterion being the user's need for the source).

Standards "b" and "c" result from the distribution rule 20/80 stating that about $20 \%$ of the sources satisfies about $80 \%$ of the needs.

Separate indicators should be prepared for individual discipline or groups of disciplines. These indicators should then be updated with the passing time (every second or third year at the best). The form of the indicator is the canon of books for a field of study for a given period of time. Alternatively, a simplified indicator can also be adopted, i.e. the approximate number of titles. It is necessary, however, to work out rules for constructing the canon for a given discipline and rules telling how to make use of it. An even simpler method would be to state a minimal sum for acquisition of sources of information, for example, per user. But the decision as to the amount of that sum requires knowledge on the literature in a given discipline. Of course, this may counteract the decrease in the amount of funds apportioned to acquisition, but it does not force a library to rationalise purchases. The attractiveness of the indicator results entirely from its simplicity which is, apparently, its sole advantage.

2) Quality standards for the organizational and technological platform a/ maximum and average time to process a request within information services (loan processing, time needed for access to a terminal on the premises of the library, time needed for a getting a seat in a reading room), $\mathrm{b} /$ acceptable percentage of non-processed orders (for sources that are declared to be accessible in the system, for example, those that are recorded in the catalogue), $\mathrm{c} /$ maximum and average time of the preparation of a source for being made available.

Finally, the technological norms should regulate the key processes determining how they will be facilitated and regulated. It should determine which processes are critical and a suitable plan of procedures dealing with them should be worked out. For example, there is only a slight chance for a mistake which would eliminate access to a source to be made in the preparation process. Acquisition is a process in which cardinal errors and ensuing complications are possible, e.g. selection of an inaccurate source, purchasing the right source involving too much cost, or unnecessary doubling of the source, prolonged process of source acquisition.

\section{Auxiliary standards pertaining to access to resources and the service of the} resources are to help the management of the library plan further functioning of the library. However, they should not be considered to be binding. Below we enumerate only some examples of standards which are of some interest to managing staff of the library:

a) the number of seats in reading rooms in relation to the size of the resources in printed form and to the number of users

b) the loan time in relation to the number of users and to the size of the resources in printed form

c) the number of volumes in relation to the number of users 
d) the number of access hours to terminals on the premises of the university in relation to the number of users and the size of the electronic resources

e) the number of posts in acquisition departments, library preparation division, and stockroom in relation to the type of material (printed, electronic, possessed by the library, from outside of the library) and to the size of the resources,

The indicators should be worked out in the form of algorithms that would enable calculations of the value of the indicator for a given set of conditions. The indicators pertaining to costs can also have a provisional character. They can be worked out on the basis of averaged data obtained from libraries in Poland and abroad. The data should be comparable. It is important to establish in which point of the system measurements are taken and what is a possible form of the indicator.

\section{Conclusions and plans for the future}

The decade of the 1990s was the time of radical change for Polish libraries and intensive work with the implementation of library systems. In parallel, organizational structures underwent reorganisation and co-operation was being developed in making joint access to electronic sources available. All these changes and the specific financial situation as well as the guiding principles of focusing on the user made the discussion on performance and the improvement of the quality of service in libraries a topical subject. Incidentally, these discussions took place in fairly favourable conditions for the formation of the procedures for the evaluation of the institutions of higher education in Poland. For example, extra funding from the budget of the state according to a specified algorithm which took into consideration library services, or the emergence of the State Accreditation Commission. However, the adopted criteria and the algorithms given are very general and vague, sometimes even misleading. Thus, the library community has initiated works targeted at working out reliable methods of evaluation of libraries and the selected standards in their functioning applicable to all Polish libraries.

The Task Group for Standardization has assumed the following parallel channels of continuous work, targeting at:

1) carrying out a several-year comparative study on research and scientific libraries based of the above-described computer program. The study will allow us to draw conclusions on performance indicators over a considerable period of time and to make an attempt to work out advisable standards applicable in the country.

2) conducting baseline studies whose aim is to work out practicable methods in library evaluation that would be helpful for managements of libraries and the superior authorities alike.

The results of the study will also have a beneficial influence on Polish libraries, which will have to comply with the standards currently in force in member countries of the EU. All the work carried by the Group is done in relation to the results of similar studies in other countries and to international standards. The authors wish to express their hope that a closer co-operation with similar task groups in other countries may follow in immediate future within joint projects both in library statistics and performance evaluation studies. 


\section{References}

Abbott, Ch. (1994), Performance Measurement in Library and Information Services, ASLIB, London.

ACRL Standards \& Guidelines (2003), URL:

http://www.ala.org/Content/NavigationMenu/ACRL/Standards and Guidelines/Stand ards and Guidelines.htm.

Archive of the Electronic Collection (2000), URL:

http://www.bg.agh.edu.pl/BG/skrypty/index.html.

Blixrud, J. C. (2001), The Association of Research Libraries Statistics and Measurement Program: From Descriptive Data to Performance Measurement. $67^{\text {th }}$ IFLA Council and General Conference. August 16-25, 2001 [Online], Available: http://www.ifla.org/IV/ifla67/papers/034-135e.pdf [17/09/2003].

CAUL Council of Australian University Librarians (2003), Performance Indicators URL: http://www.anu.edu.au/caul/best-practice/PerfInd.html.

Cullen R.J., Calvert P.J. (1995), Stakeholder Perception of University Library Effectiveness. The Journal of Academic Librarianship. Vol. 21, Issue 6, pp. 438-448.

Deutsche Bibliotheks Statistik (2003), URL: http://www.bibliotheksstatistik.de/.

Digital Library of Wielkopolska (2002), URL: http://www.wbc.poznan.pl/index.html.

The Effective Academic Library. A Framework for Evaluating the Performance of UK Academic Libraries (1995), HEFCE Publications, Bristol.

Electronic Service for Librarians (1999), URL:

http://ebib.oss.wroc.pl/english/index.php.

Górny M, Jazdon A. (1997), The Implementation of Information Technology Projects in Polish Research and Academic Libraries in the early 1990 s. Questions of Scope and Effectiveness. Library Management. Vol. 18, No. 6, pp.280-285.

EQUINOX (2002), Library Performance Measurement and Quality Management System. URL: http://equinox.dcu.ie/index.html.

The Follett Report (1993), URL:

http://www.ukoln.ac.uk/services/papers/follett/report/.

Górny M., Jazdon A., Nowak P., (1999), Selected Indicators of the Range and Use Printed Resources in Polish Academic Libraries. Library Management Vol.20, No. 3/4, pp.159-167.

Guidelines for College Libraries. Recommendations for Performance and Resourcing (1995), Library Association, London.

IPEDS - The Integrated Postsecondary Education Data System (2003). URL:

http://nces.ed.gov./ipeds,

ISO 11620: (1998) Information and Documentation: Library Performance Indicators.

KaRo - Distributed Catalog of Polish Libraries (2001), URL:

http://karo.umk.pl/Karo/karo.php?al=x\&lang=en 
Kniffel L. (2001), Twelve Years after the Fall: Poland's Complicated Transition. American Libraries, Vol. 32, Issue 1, pp.64-68.

Kokkonen O. (1996), Performance Measurement at National Level: Problems of Quality Approach. In: Library Management and Information Technology.

Proceedings of the Seminar held in Vilnius, Lithuania May 27-29, 1996, pp. 34-44.

The LibEcon2000 survey questionnaires (2000), URL:

http://www.libecon2000.org/survey/default.asp.

Modern Libraries and Librarianship in Poland. (1995), Ed. by Maria Kocójowa and Alicja Altenberger, Kraków.

National Union Catalog NUKAT (2001), URL: http://www.nukat.edu.pl/katalog/.

Poll R. (2001), Managing Service Quality with the Balanced Scorecard. In: $67^{\text {th }}$ IFLA Council and General Conference. August 16-25, 2001 [Online]. Available: http://www.ifla.org/IV/ifla67/papers/042-135e.pdf [17/09/2003].

Research Libraries - Cooperation in Automation (1999), Ed. by Jadwiga Woźniak and Robert C. Miller. Warsaw

Statistical Year Book. (2002) Warsaw, p. 315.

Treasury of Polish Literature (1999), URL: http://www.literatura.zapis.net.pl/.

Virtual Library of Polish Literature (2000), URL: http://julia.univ.gda.pl/ literat/.

Virtual Scientific Library (2003), URL: http://vls.icm.edu.pl/. 